\title{
Phenotypic Variability of the Sensitivity to Cycloserine of Klebsiella aerogenes NCTC 418, Growing in Chemostat Culture
}

\author{
By AART STERKENBURG* AND JAN T. M. WOUTERS \\ Laboratorium voor Microbiologie, Universiteit van Amsterdam, Nieuwe Achtergracht 127 , \\ 1018 WS Amsterdam, The Netherlands
}

(Received 30 June 1980; revised 6 October 1980)

\begin{abstract}
The susceptibility of Klebsiella aerogenes to cycloserine varied according to the growth conditions. In batch culture, cells were less susceptible to the antibiotic when glycine was present in the medium, presumably due to competition between glycine and cycloserine for the uptake system by which glycine, D-alanine and cycloserine are transported into the cell. In the chemostat at average dilution rates, ammonia-limited cultures were more susceptible to the antibiotic than were glucose-limited cultures. Under phosphate-limiting conditions cultures were at least ten times less susceptible. Under ammonia and phosphate limitation the susceptibility increased with increasing growth rate. The sensitivity of glucose-limited cells was independent of the growth rate. A high-affinity uptake system for cycloserine (as measured by D-alanine transport) was present in ammonia- and glucose-limited cells, but not in phosphate-limited cells. Thus. the phenotypically defined alterations in the susceptibility of the bacterium to cycloserine could be correlated with variations in its uptake system for the antibiotic.
\end{abstract}

\section{INTRODUCTION}

Alterations in the composition of the bacterial envelope can involve decreased activities of uptake systems by which antibiotics penetrate the cell and, hence, can lower the susceptibility of the bacteria to these agents (Melling \& Brown, 1975). The composition of the envelope can be influenced markedly by the bacterial growth conditions (Brown \& Melling, 1969; Robinson \& Tempest, 1973) and, consequently, environmental parameters may affect the bacterial sensitivity to antimicrobial agents. For purposes of correlating the antibiotic sensitivity of an organism with its growth conditions, we have used chemostat cultures. With this technique, well-defined growth conditions can be imposed on a culture (Tempest, 1970). The chemostat has already proved to be an excellent tool in studies of the phenotypically defined response of Pseudomonas aeruginosa (Finch \& Brown, 1975; Gilbert \& Brown, 1978), Escherichia coli (Koch \& Gross, 1979) and Candida albicans (Johnson et al. 1978) to various agents.

In this study, the sensitivity of growing cultures of Klebsiella aerogenes to cycloserine has been investigated. The inhibition of peptidoglycan synthesis caused by this antibiotic may be regarded as a result of the competitive action between cycloserine and $\mathrm{D}$-alanine for the enzymes alanine racemase and D-alanyl-D-alanine synthetase (Franklin \& Snow. 1975). A similar competition has been observed for the uptake system by which the amino acids D-alanine and glycine, as well as the antibiotic cycloserine, are transported into the cell (Wargel et al., 1970). The resistance of E. coli (Wargel et al.. 1971), Bacillus subtilis (Clark \& Young, 1977) and Rhizobium sp. (Pankhurst \& Craig, 1979) to cycloserine has been shown to be coupled with variations in this uptake system. During the course of the present investigation, alterations in the uptake system by which cycloserine may penetrate the cell 
have been found to play a major role in the phenotypic variability of the sensitivity of $K$. aerogenes to this antibiotic.

\section{METHODS}

Organism. Klebsiella aerogenes NCTC 418 was maintained by monthly subculture on nutrient agar.

Growth conditions. Organisms were grown aerobically in nutrient broth or in simple salts media. The latter were basically as described by Evans et al. (1970). For batch cultures, the simple salts medium was enriched with $50 \mathrm{~mm}-\mathrm{NaH}_{2} \mathrm{PO}_{4}$ and the $\mathrm{pH}$ was adjusted to 7 . For continuous cultures, simple salts media were used, the amount of growth-limiting nutrient being adjusted to provide the desired steady state cell concentration. The media contained $1 \mathrm{~g}$ glucose $1^{-1}$ (glucose-limited) or $15 \mathrm{~g}$ glucose $\mathrm{l}^{-1}$ (other limitations). Cells were grown in a $600 \mathrm{ml}$ chemostat (L.H. Engineering Co., Stoke Poges); this was termed the growth fermenter. The pH value of the culture was monitored in situ and was automatically maintained at $6.8 \pm 0.1$ by addition of $1 \mathrm{M}-\mathrm{NaOH}$ (phosphate limitation) or $4 \mathrm{M}-\mathrm{NaOH}$ (other limitations). The temperature was set at $37^{\circ} \mathrm{C}$. Samples were withdrawn when the culture had reached a steady state.

Equipment for susceptibility tests. For susceptibility tests of continuous cultures a $300 \mathrm{ml}$ chemostat was used (Bioflo; NB Scientific, New Brunswick, N.J., U.S.A.); this was termed the test fermenter. Temperature, $\mathrm{pH}$ value and dilution rate $(D)$ were set at exactly the same values as those imposed on the culture in the growth fermenter. Medium withdrawn from the supply tank of the growth fermenter was used. In addition, a cycloserine stock solution was connected via a delta pump with constant flow. The concentration of this solution was chosen such that with the given flow rate of the delta pump $\left( \pm 5 \mathrm{ml} \mathrm{h}^{-1}\right.$, measured exactly) and the given dilution rate of the culture the desired final concentration of cycloserine in the test fermenter was maintained. Unequal distribution of medium, $\mathrm{NaOH}$ and cycloserine due to foaming of the culture was avoided by adding them through a common tube, by means of which air was also passed into the chemostat. Samples of the overflowing culture were taken immediately after leaving the chemostat and their turbidity was measured at $540 \mathrm{~nm}$ (Gilford Instrument Laboratories, Oberlin, Ohio, U.S.A.).

Susceptibility testing. In batch experiments, cell samples from overnight cultures or chemostat cultures were transferred to side-arm Erlenmeyer flasks with medium and allowed to grow at $37^{\circ} \mathrm{C}$ for at least 3 generations. When cultures were in the early-exponential phase of growth, cycloserine was added and the turbidity was measured at $540 \mathrm{~nm}$ (Vitatron Scientific, Dieren, The Netherlands). The minimal inhibitory concentration (m.i.c.) of the antibiotic was defined as the lowest concentration causing an eventual cessation of growth.

For susceptibility tests of continuous cultures, samples $(350 \mathrm{ml})$ were withdrawn from the growth fermenter and transferred immediately to the test fermenter. When the turbidity of the overflowing culture of the latter chemostat was constant in time, an amount of stock solution of cycloserine was added (less than $1 \mathrm{ml}$ ). depending on the desired final antibiotic concentration in the chemostat. Simultaneously, the cycloserine supply pump was started. The turbidity of the overflowing culture was followed for at least 0.75 of the initial bacterial doubling time (i.e. for at least $3 \mathrm{~h}$ ). The results were plotted as a fraction of the initial turbidity against the number of generations, thus facilitating a comparison of results obtained from cultures with different steady state turbidities and different growth rates. Since sterilization of the test system was not necessary, successive experiments could be performed relatively frequently.

$\mathrm{D}-\left[{ }^{14} \mathrm{C}\right]$ Alanine uptake measurements. A $50 \mathrm{ml}$ sample was withdrawn from the growth fermenter, centrifuged without cooling at $12000 \mathrm{~g}$ for $20 \mathrm{~min}$ in a Sorvall RC2-B centrifuge (Ivan Sorvall, Norwalk. Conn., U.S.A.) and the cells were resuspended in $25 \mathrm{ml}$ prewarmed buffer $(100 \mathrm{~mm}$-imidazole. $\mathrm{HCl}, 1 \%(\mathrm{w} / \mathrm{v})$ glucose, $\mathrm{pH} 7 \cdot 0)$. At $t=$ $0,2.5 \mathrm{ml}$ cell suspension was transferred to a $50 \mathrm{ml}$ Erlenmeyer flask containing $2.5 \mathrm{ml}$ of a D-[U- ${ }^{14} \mathrm{C} /$ alanine (The Radiochemical Centre, Amersham) solution (specific activity $0 \cdot 1-0.5 \mathrm{GBq} \mathrm{ml}^{-1}$ ) prewarmed at $37^{\circ} \mathrm{C}$. In general, the specific activity of this mixture was sufficient to give cell samples with an activity of at least 1000 c.p.m. Samples of $100 \mu \mathrm{l}$ were withdrawn at $30 \mathrm{~s}$ intervals for up to $2 \mathrm{~min}$, filtered immediately through a $0.2 \mu \mathrm{m}$ membrane filter and washed twice with $1 \mathrm{ml} 0.9 \%(\mathrm{w} / \mathrm{v}) \mathrm{NaCl}$ solution. After drying overnight at $50{ }^{\circ} \mathrm{C}$, samples were counted by liquid scintillation in a toluene/Omnifluor (New England Nuclear, Boston, Mass., U.S.A.) mixture. Initial rates of $\mathrm{D}$-alanine uptake were calculated. A correction was made for the uptake rate that was found for boiled cells or cells that had been treated for at least $10 \mathrm{~min}$ with $10 \mathrm{~mm}$-sodium azide.

\section{RES ULTS}

\section{Susceptibility in batch cultures}

The effect of cycloserine, when added to cultures of $K$. aerogenes in the early-exponential phase of growth, was strongly dependent on the composition of the growth medium. In nutrient broth, the m.i.c. of cycloserine was $110 \mu \mathrm{g} \mathrm{ml}^{-1}$, whereas in minimal salts medium the 


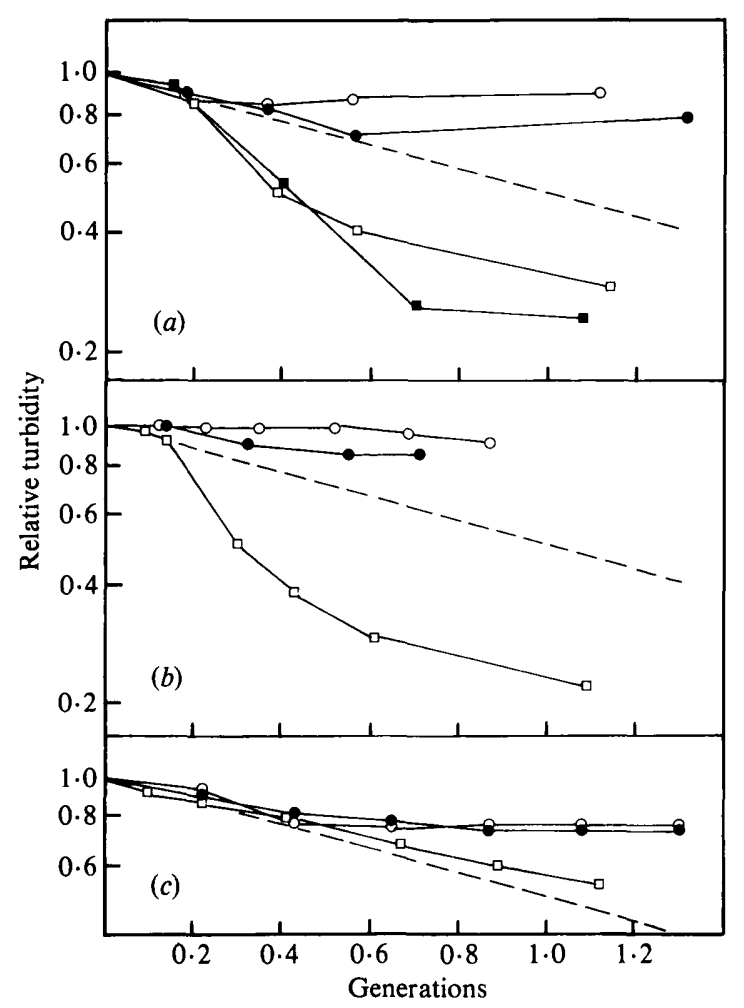

Fig. 1. Influence of growth limitation on the susceptibility of Klebsiella aerogenes to cycloserine. The turbidity of ammonia-limited $(a)$, glucose-limited $(b)$ and phosphate-limited $(c)$ cultures was measured during exposure to various concentrations of cycloserine, as described in Methods. Applied cycloserine concentrations: in $a\left(D=0.4 \mathrm{~h}^{-1}\right), 0.5 \mu \mathrm{g} \mathrm{m}^{-1}(O), 1 \mu \mathrm{g} \mathrm{ml}^{-1}(O), 2 \mu \mathrm{g} \mathrm{ml}^{-1}(\square)$ and $4 \mu \mathrm{g} \mathrm{ml}^{-1}(\square)$ : in $b, 1 \mu \mathrm{g} \mathrm{ml}^{-1}\left(\mathrm{O}, D=0.2 \mathrm{~h}^{-1}\right), 3 \mu \mathrm{g} \mathrm{ml}^{-1}\left(\mathrm{O}, D=0.3 \mathrm{~h}^{-1}\right)$ and $5 \mu \mathrm{g} \mathrm{ml} \mathrm{l}^{-1}\left(\square, D=0.3 \mathrm{~h}^{-1}\right)$ : in $c(D=$ $\left.0.3 \mathrm{~h}^{-1}\right), 12 \mu \mathrm{g} \mathrm{ml}^{-1}(\mathrm{O}), 40 \mu \mathrm{g} \mathrm{ml}^{-1}$ (O) and $80 \mu \mathrm{g} \mathrm{ml}^{-1}$ (口). In each case, the wash-out curve according to the dilution rate is represented by the dashed line.

m.i.c. was $11 \mu \mathrm{g} \mathrm{ml}^{-1}$. When the minimal salts medium was supplemented with $7 \mathrm{~mm}$-glycine, comparable with the glycine concentration in nutrient broth, the m.i.c. was increased to $128 \mu \mathrm{g} \mathrm{ml}^{-1}$. This indicated that glycine probably acted as a competitor for the uptake system by which cycloserine was entering the bacteria.

\section{Susceptibility in chemostat cultures}

Influence of growth limitation on the susceptibility to cycloserine. After transfer from the growth fermenter to the test fermenter, cultures usually attained a steady state, as determined by turbidity measurements, within $30 \mathrm{~min}$. In order to evaluate the results of our experiments, the kinetics were determined by which the turbidity of the chemostat culture decreased after a sudden change in the composition of the inflowing medium resulting in bacteriostasis. For this, the bacterial growth was stopped either by omitting the growth limiting nutrient or by supplementing the medium with $40 \mu \mathrm{g}$ chloramphenicol $\mathrm{ml}^{-1}$. This resulted in a rate of wash-out of cells from the chemostat that was not higher than the theoretically predicted wash-out rate (data not shown), indicating the absence of lysis under these conditions.

Susceptibility to cycloserine was examined during growth of $K$. aerogenes under ammonia, glucose and phosphate limitations. Ammonia-limited cultures were the most sensitive: cycloserine added at $0.5 \mu \mathrm{g} \mathrm{ml}^{-1}$ to cultures growing at $D=0.4 \mathrm{~h}^{-1}$ led to a decrease in the turbidity of the culture, and with cycloserine at $2 \mu \mathrm{g} \mathrm{m}^{-1}$ cell lysis took place (Fig. $1 a$ ). Under 


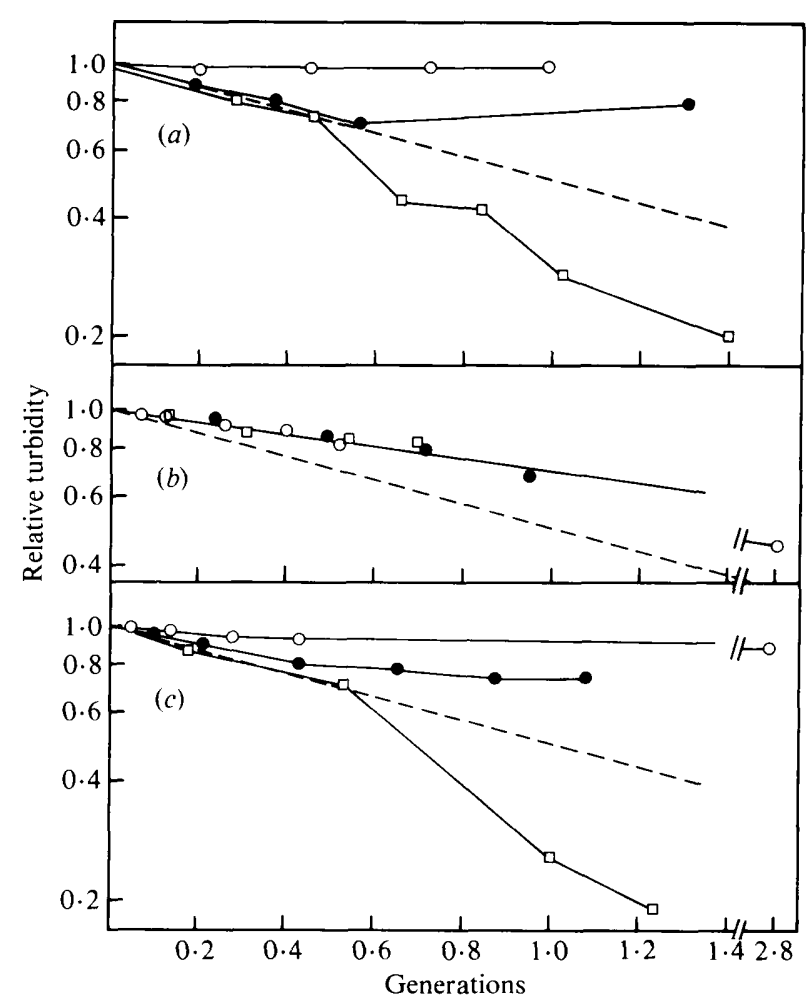

Fig. 2. Influence of growth rate on the susceptibility of Klebsiella aerogenes to cycloserine. The turbidity of ammonia-limited $(a)$, glucose-limited $(b)$ and phosphate-limited $(c)$ cultures was measured during exposure to 1.3 and $40 \mu \mathrm{g}$ cycloserine $\mathrm{ml}^{-1}$. respectively, as described in Methods. Imposed growth rates: in $a .0 \cdot 2 \mathrm{~h}^{-1}(\mathrm{O}) .0 \cdot 4 \mathrm{~h}^{-1}(O)$ and $0.8 \mathrm{~h}^{-1}(\square):$ in $b$ and $c .0 \cdot 1 \mathrm{~h}^{-1}(O) .0 \cdot 3 \mathrm{~h}^{-1}(O)$ and $0 \cdot 5 \mathrm{~h}^{-1}(\square)$. In each case, the wash-out curve according to the dilution rate is represented by the dashed line.

glucose-limited conditions ( $\left.D=0.3 \mathrm{~h}^{-1}\right) K$. aerogenes was slightly less sensitive to cycloserine: $3 \mu \mathrm{g}$ cycloserine $\mathrm{ml}^{-1}$ led to a decrease in the culture turbidity but lysis was not observed until the antibiotic concentration was raised to $5 \mu \mathrm{g} \mathrm{m}^{-1}$ (Fig. $1 \mathrm{~b}$ ). Cycloserine at $12 \mu \mathrm{g} \mathrm{ml}^{-1}$ in phosphate-limited cultures $\left(D=0.3 \mathrm{~h}^{-1}\right)$ caused only a slight decrease in the turbidity of the culture and even $40 \mu \mathrm{g}$ cycloserine $\mathrm{ml}^{-1}$ had no lasting growth inhibiting effect; with $80 \mu \mathrm{g} \mathrm{ml}^{-1}$ there was severe growth inhibition, but without any lysis occurring (Fig. 1c).

Influence of growth rate on the susceptibility to cycloserine. The turbidity of ammonialimited cultures growing at $D=0.4 \mathrm{~h}^{-1}$ decreased when the growth medium was supplemented with $1 \mu \mathrm{g}$ cycloserine $\mathrm{ml}^{-1}$. but subsequently growth restarted (Fig. $1 \mathrm{a}$ ). However, at a higher dilution rate $\left(0.8 \mathrm{~h}^{-1}\right)$, addition of this concentration of antibiotic led to cell lysis. In contrast, at a lower dilution rate $\left(0 \cdot 2 \mathrm{~h}^{-1}\right)$, the presence of $1 \mu \mathrm{g}$ cycloserine $\mathrm{ml}^{-1}$ had no effect (Fig. $2 a$ ). The same phenomenon was observed under phosphate limitation when $40 \mu \mathrm{g}$ cycloserine $\mathrm{ml}^{-1}$ was added to the growth medium (Fig. $2 c$ ). In contrast to these findings, the reaction of glucose-limited cultures upon addition of $3 \mu \mathrm{g}$ cycloserine $\mathrm{ml}^{-1}$ appeared to be independent of the bacterial growth rate (Fig. $2 b$ ).

Influence of growth conditions on the activity of the D-alanine uptake system

To investigate a possible correlation between the susceptibility to cycloserine and its uptake by the cells, alanine was used as a probe of the activity of the transport system. The initial rate 


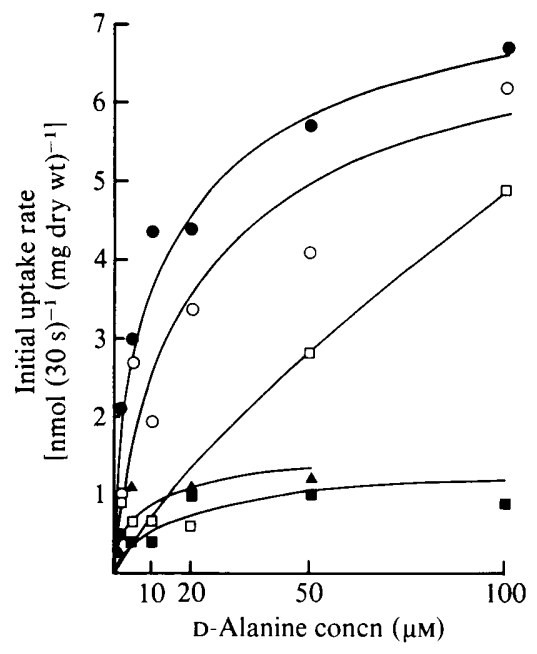

Fig. 3. Uptake of D-alanine by Klebsiella aerogenes grown under ammonia limitation at $D=0 \cdot 1 \mathrm{~h}^{-1}$ (O) and $D=0.3 \mathrm{~h}^{-1}(\mathrm{O})$, glucose limitation at $D=0.3 \mathrm{~h}^{-1}(\mathbf{\Delta})$ and phosphate limitation at $D=$ $0 \cdot 1 \mathrm{~h}^{-1}(\boldsymbol{\square})$ and $D=0.6 \mathrm{~h}^{-1}(\square)$.

of uptake, which depended on the input concentration of alanine, varied with the growth conditions of the bacteria (Fig. 3). Ammonia-limited cells exhibited a relatively high uptake rate, while the accumulation of the amino acid by glucose-limited cells and slowly growing phosphate-limited cells $\left(D=0 \cdot 1 \mathrm{~h}^{-1}\right)$ was considerably slower. Phosphate-limited cells growing at a high dilution rate $\left(D=0.6 \mathrm{~h}^{-1}\right)$ had an intermediate uptake rate. The D-alanine uptake rate was dependent on the growth rate. Ammonia-limited cells grown at $D=0 \cdot 1 \mathrm{~h}^{-1}$ exhibited an uptake rate that was higher than that of cells grown at a higher dilution rate. Conversely, slowly growing phosphate-limited cells had a less active uptake system than fast growing ones.

A transformation of the curves shown in Fig. 3 into Lineweaver-Burk plots yielded straight lines for phosphate-limited cultures, but non-linear curves for ammonia- and glucose-limited cultures (Lineweaver-Burk plots not shown). The latter were interpreted as indicating the occurrence of more than one uptake system with different apparent $K_{\mathrm{m}}$ values. Extrapolation of the plots for ammonia- and glucose-limited cultures yielded a high-affinity apparent $K_{\mathrm{m}}$ value of about $1.4 \times 10^{-6} \mathrm{M}$ and a low-affinity one in the range $1-10 \times 10^{-5} \mathrm{M}$. In phosphate-limited cultures only a low-affinity apparent $K_{\mathrm{m}}$ value was indicated, which also was in the range $1-10 \times 10^{-5} \mathrm{M}$.

\section{DIS CUS SION}

Both the nature of the nutrient which was limiting growth and the growth rate had a striking effect on the response of $K$. aerogenes growing in the chemostat to cycloserine (see Fig. 1, 2). Wargel et al. (1970) found both high- and low-affinity systems in batch-grown cultures of $E$. coli for the accumulation of D-alanine, glycine and cycloserine. Our results also indicate the presence of both high-and low-affinity components in the uptake system of $K$. aerogenes cells grown under ammonia or glucose limitation. However, under phosphate-limiting conditions. the high-affinity component was absent. This was coupled with a phenotypically defined decrease in sensitivity to cycloserine that was comparable with the decrease in susceptibility to this antibiotic found in a mutant, $c y c^{r 1}$, of $E$. coli which had lost the high-affinity component of the uptake system (Wargel et al., 1970; Curtiss et al., 1965). The increase in susceptibility to cycloserine of ammonia-limited cultures with increasing growth rate could not be correlated 
directly with the decreasing D-alanine uptake rate under these conditions. Obviously, the process underlying this response cannot be attributed to alterations in cycloserine uptake alone.

The occurrence of a high-affinity component in the uptake system for D-alanine may be seen as a physiologically relevant process under those conditions when growth is limited by a restricted supply of the nitrogen, carbon or energy source, resulting in a rapid uptake of cycloserine and, as a consequence, a greater sensitivity of the organism to the antibiotic.

A phenotypically defined sensitivity of a bacterial strain to an antibiotic may have serious implications for antimicrobial chemotherapy. Clinical procedures for susceptibility testing are routinely based on in vitro growth conditions of the strain that is to be tested. However, growth conditions in vivo - for instance, in an infected part of the human body - are assumed to be sub-optimal as a result of a limited supply of some essential nutrients (Brown, 1977). The results described in this report show a strong dependency of the bacterial susceptibility to antibiotics on the growth conditions of the culture, and therefore a routine testing system may give only an indication of the in vivo inhibitory concentration.

In our experiments, cycloserine was added to a steady state chemostat culture thereby disturbing the steady state and imposing new, constant growth conditions. The culture either reached a new steady state or was washed-out. A new steady state may have been accompanied by modified yields on nutrients, and a wash-out may be regarded as an expression of a new, lower maximal specific growth rate. However, we have little knowledge of these new parameters and, therefore, of the processes which occur during the transient state. The new parameters may be evaluated by the use of long-term experiments, but these have the disadvantage that the culture might either become 'trained' to a certain concentration of cycloserine (Clark \& Young, 1977) or even that resistant mutants may arise.

\section{REFEREN CES}

Brown, M. R. W. (1977). Nutrient depletion and antibiotic susceptibility. Journal of Antimicrobial Chemotherapy 3, 198-201.

Brown, M. R. W. \& Melling, J. (1969). Role of divalent cations in the action of polymyxin $\mathrm{B}$ and EDTA on Pseudomonas aeruginosa. Journal of General Microbiology 59, 263-274.

Clark, V. L. \& Young, F. E. (1977). Inducible resistance to D-cycloserine in Bacillus subtilis 168 . Antimicrobial Agents and Chemotherapy 11, 871876.

Curtiss III, R., Charamella, L. J., Berg, C. M. \& HARRIS, P. E. (1965). Kinetic and genetic analyses of D-cycloserine inhibition and resistance in Escherichia coli. Journal of Bacteriology 90, 12381250.

Evans, C. G. T., Herbert, D. \& Tempest, D. W. (1970). The continuous cultivation of microorganisms. 2. Construction of a chemostat. Methods in Microbiology 2, 277-327.

Finch, J. E. \& Brown. M. R. W. (1975). The influence of nutrient limitation in a chemostat on the sensitivity of Pseudomonas aeruginosa to polymyxin and to EDTA. Journal of Antimicrobial Chemotherapy 1, 379-386.

Franklin, T. J. \& SNow, G. A. (1975). Biochemistry of Antimicrobial Action. London: Chapman \& Hall.

Gilbert, P. \& Brown, M. R. W. (1978). Influence of growth rate and nutrient limitation on the gross cellular composition of Pseudomonas aeruginosa and its resistance to 3- and 4-chlorophenol. Journal of Bacteriology 133, 1066-1072.
Johnson, B., White, R. J. \& Williamson, G. M. (1978). Factors influencing the susceptibility of Candida albicans to the polyenoic antibiotics nystatin and amphotericin B. Journal of General Microbiology 104, 325-333.

KocH, A. L. \& Gross, G. H. (1979). Growth conditions and rifampin susceptibility. Antimicrobial Agents and Chemotherapy 15, 220-228.

Melling, J. \& Brown, M. R. W. (1975). The effect of the bacterial environment on resistance. In Resistance of Pseudomonas aeruginosa, pp. 35-69. Edited by M. R. W. Brown. London: John Wiley.

Pankhurst, C. E. \& Craig, A. S. (1979). Morphology and nitrogenase activity of agar cultures and root nodules formed by $\mathbf{D}$-cycloserineresistant mutants of Rhizobium sp. strain $32 \mathrm{H} 1$. Journal of General Microbiology 110, 177-184.

Robinson, A. \& Tempest, D. W. (1973). Phenotypic variability of the envelope proteins of Klebsiella aerogenes. Journal of General Microbiology $\mathbf{7 8}$, 361-370.

Tempest, D. W. (1970). The continuous cultivation of microorganisms. 1. Theory of the chemostat. Methods in Microbiology 2, 259-276.

Wargel, R. J., Shadur, C. A. \& Neuhaus, F. C. (1970). Mechanism of D-cycloserine action: transport systems for $\mathrm{D}$-alanine, $\mathrm{D}$-cycloserine, $\mathrm{L}$-alanine, and glycine. Journal of Bacteriology 103, 778-788.

Wargel, R. J., Shadur, C. A. \& Neuhaus, F. C. (1971). Mechanism of D-cycloserine action: transport mutants for D-alanine, D-cycloserine, and glycine. Journal of Bacteriology 105, 1028-1035. 